\title{
Constraint on the recurrence of great outer-rise earthquakes from seafloor bathymetry
}

\author{
Norman H. Sleep \\ Department of Geophysics, Stanford University, Stanford, California, USA \\ (Received January 19, 2012; Revised July 26, 2012; Accepted July 31, 2012; Online published January 28, 2013)
}

\begin{abstract}
Great outer rise earthquakes are a tsunami hazard as they occur on steeply dipping faults (Lay et al., 2009). The largest instrumentally recorded of these events are the 1933 Sanriku Japan earthquake $\left(M_{\mathrm{w}}=8.4\right)$ and 1977 Sumba Indonesia earthquake $\left(M_{\mathrm{w}}=8.3\right)$ (Lay et al., 2009). Seafloor bathymetry (Kobayashi et al., 1998) and plate kinematics indicate a great $M_{\mathrm{w}} \geq 8$ outer rise earthquake on the zone of the great Tohoku $M_{\mathrm{w}} 9$ event can occur at most once in 7 megathrust cycles.
\end{abstract}

Key words: Triggered earthquakes, normal faults, subduction, earthquake risk.

\section{Introduction}

The purpose of this note is to use plate kinematics to constrain the relative rates of moment release on megathrust and outer-rise earthquakes, and hence obtain a kinematic constraint on the relative frequency of recurrence of the latter. I concentrate on the Kurile and northern Japanese trenches because data are available and because the recent Tohoku $\left(M_{\mathrm{w}}=9.0\right)$ event increased concern about tsunami-producing normal faulting events (Lay et al., 2011).

\section{Plate Kinematics}

Physically, great megathrust earthquakes increase intraplate horizontal tension on the outer rise and may trigger very large earthquakes. The 13 January 2007 normal $\left(M_{\mathrm{w}}=8.1\right)$ faulting event occurred seaward of the 15 November $2006\left(M_{\mathrm{w}}=8.3\right)$ Kurile megathrust event (Lay et al., 2009). Conversely, the 2009 Samoa event occurred with megathrust event on the Tonga subduction zone (Beavan et al., 2010; Lay et al., 2010). Thrusting occurred immediately after the normal faulting (Lay et al., 2010).

I present a kinematic method involving potency rate, that is fault area times slip rate. I assume that earthquakes accommodate the bulk of the slip and the elastic constants do not vary greatly so that moment release rate scales with the potency rate obtained from the long-term slip on faults. I treat the trench and outer rise as two-dimensional features for simplicity.

The long-term kinematics of the Japan and Kurile megathrust are relatively simple as one macroscopic fault accommodates the slip. The shallowly dipping seismogenic fault has a length $T$ of $\sim 200 \mathrm{~km}$ along dip (Fig. 1). The plate slips at a rate $U$ of $\sim 80 \mathrm{~mm} / \mathrm{yr}$. So the rate of potency

Copyright (c) The Society of Geomagnetism and Earth, Planetary and Space Sciences (SGEPSS); The Seismological Society of Japan; The Volcanological Society of Japan; The Geodetic Society of Japan; The Japanese Society for Planetary Sciences; TERRAPUB.

doi:10.5047/eps.2012.07.011 release per strike length on the fault is $T U$. The moment release rate per length is the quantity times the shear modulus $G$.

Numerous faults cut the outer rise producing numerous horsts and graben. The total slip on these faults is relevant for potency release. I proceed with a method that does not require knowing when particular faults slipped. Kobayashi et al. (1998) obtained detailed bathymetric maps of seafloor approaching the Kurile and Japan trenches. Faults dip both toward and away from the trench. I sum the absolute values of their vertical throws on maps to obtain the absolute value of fault throw per length perpendicular to the trench. In convenient map units the throw $H=\sim 300 \mathrm{~m}$ per $X=$ $10 \mathrm{~km}$ of seafloor across strike. The total throw along the dip of the fault is somewhat larger and comparable. I do not distinguish it from $H$ to avoid spurious precision.

The net horizontal strain from this process is that expected from a bending plate. The horizontal throw on a fault is less than but comparable to the vertical throw. So the horizontal strain is $\sim H / X$ or $\sim 3 \%$. The bending strain is $Y / R$ the ratio of the depth to the neutral plane of the flexed plate to its radius of curvature. The seismically active part of these faults extends down to $F=\sim 30 \mathrm{~km}$ along dip (Lay et al., 2009). The neutral plane is likely at a comparable but somewhat deeper depth. The radius of curvature from the maps of Kobayashi et al. (1998) is $\sim 1000 \mathrm{~km}$. So the bending strain is also $\sim 3 \%$.

The potency rate is obtained by noting that pristine seafloor enters the outer rise at the subduction rate $U$ and exits into the trench with horizontal strain and absolute throw per length of $H / X$. The throw production rate per strike length is $H U / X=2.4 \mathrm{~mm} / \mathrm{yr}$. The same rate is obtained by considering the whole width of the outer rise $W$. The absolute value of throw across the outer rise is $H W / X$ and seafloor remains in the outer rise over a time $W / U$. That is, the time averaged throw production for a batch of seafloor equals the spatial averaged rate of throw production across the outer rise. The potency release per strike length 


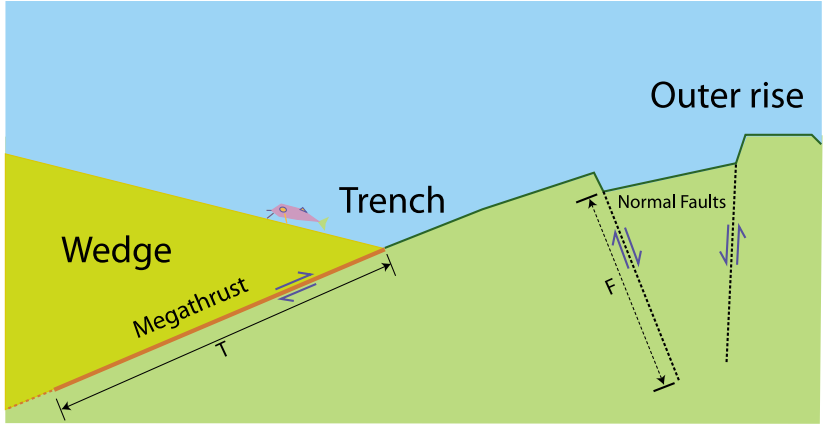

Fig. 1. Schematic diagram of geometry of megathrust and outer rise. Not to scale. There are numerous faults, horsts and graben on the outer rise and seafloor entering the trench is strongly faulted.

is $F H U / X$, where $F$ is the typical depth to the base of each of the numerous faults that cut the outer rise.

\section{Conclusion: Likelihood of Great Outer Rise Event}

The ratio of outer rise to megathrust potency (and moment) release $F H / X T=0.45 \%$. I give two example calculations to appraise hazard, using the fact that moment increases by a factor of $10^{1.5}$ for each $M_{\mathrm{w}}$ unit. First, I assume that one large outer rise event occurs after each great megathrust event, which implies that this outer rise event is $1.56 M_{\mathrm{w}}$ below the great thrust event, retaining an extra digit. Secondly, I let putative events following the Tohoku earthquake have $M_{\mathrm{w}}=$ of 8 and 8.5 . These events have $3 \%$ and $18 \%$ of the moment of the megathrust event. They can occur only once in 7 and 40 megathrust cycles. Thus, the near-term risk of a great tsunami-producing outer rise earthquake seaward of Tohoku is moderate but not negligible.

Acknowledgments. This research was supported by the Southern California Earthquake Center. SCEC is funded by NSF Cooperative Agreement EAR-0106924 and USGS Cooperative Agreement 02HQAG0008. The SCEC contribution number for this paper is 1674. Greg Beroza and Thorne Lay made helpful comments. Dr. Gou Fujie and an anonymous review made helpful comments.

\section{References}

Beavan, J., X. Wang, C. Holden, K. Wilson, W. Power, G. Prasetya, M. Bevis, and R. Kautoke, Near-simultaneous great earthquakes at Tongan megathrust and outer rise in September 2009, Nature, 466, 959-963, 2010

Kobayashi, K., M. Nakanishi, K. Tamaki, and Y. Ogawa, Outer slope faulting associated with the western Kuril and Japan trenches, Geophys. J. Int., 134, 356-372, 1998.

Lay, T., H. Kanamori, C. J. Ammon, A. R. Hutko, K. Furlong, and L. Rivera, The 2006-2007 Kuril Islands great earthquake sequence, $J$. Geophys. Res., 114, B11308, 2009.

Lay, T., C. J. Ammon, H. Kanamori, L. Rivera, K. Koper, and A. R. Hutko, The 2009 Samoa-Tonga great earthquake triggered doublet, Nature, 466, 964-968, 2010.

Lay, T., C. J. Ammon, H. Kanamori, M. J. Kim, and L. Xue, Outer trenchslope faulting and the $2011 M_{\mathrm{W}} 9.0$ off the Pacific coast of Tohoku Earthquake, Earth Planets Space, 63, 713-718, 2011.

N. H. Sleep (e-mail: norm@stanford.edu) 